\title{
Börjars and Burridge's Introducing English Grammar: Book Review
}

\author{
Edward Owusu'1, Levina Nyameye Abunya² \\ ${ }^{1}$ Department of Communication Studies, Directorate of Quality Assurance and Academic Planning, Sunyani Technical \\ University, Sunyani, Ghana \\ ${ }^{2}$ Department of Language and Communication Science, Kwame Nkrumah University of Science and Technology, Kumasi, Ghana \\ Email: edwardowusu@minister.com
}

How to cite this paper: Owusu, E. and Abunya, L.N. (2020) Börjars and Burridge's Introducing English Grammar: Book Review. Open Access Library Journal, 7: e6817.

$\underline{\text { https://doi.org/10.4236/oalib.1106817 }}$

Received: September 14, 2020

Accepted: October 19, 2020

Published: October 22, 2020

Copyright (C) 2020 by author(s) and Open Access Library Inc.

This work is licensed under the Creative

Commons Attribution International

License (CC BY 4.0).

http://creativecommons.org/licenses/by/4.0/

(c) (i) Open Access

\begin{abstract}
This paper reviews Börjars and Burridge's book, Introducing English Grammar, which is the main data of the paper [1]. Descriptive design is the methodology we used for the review. Consequently, we employed critical analysis in reviewing the chapters of the book. The review was done in an unpretentious manner to cover all the eleven chapters of the book. The paper is segmented into four parts: introduction, the thesis, the chapters, and conclusion. We believe that the critique we have provided and the comparative analysis we have done with some of the information in other grammar books would aid readers in fathoming the contents of Introducing English Grammar, by Börjars and Burridge [1].
\end{abstract}

\section{Subject Areas}

Education

\section{Keywords}

Introducing English Grammar, Book Review, Sentences, Clauses, Phrases, Words, New Englishes

\section{Introduction}

Mastery of language teaching and learning demands obligation on the part of both the learner and the facilitator, in terms of applying some rules and principles [2]. Reading of comprehensive English grammar books is one method that can facilitate comprehension of complex grammatical rules and principles. However, the complexity and voluminous nature of some materials, sometimes, make it taxing for some readers to read and digest some contents in some books. 
Accordingly, the essence of this book review is to provide a synopsis of one of the useful comprehensive English grammar books. Many authors have deployed different manoeuvres in expressing their interpretations on English grammar contents. For example, A University Grammar of English, by Quirk and Greenbaum, basically describes extensive theories of syntactical contents [3]. In addition to these extensive syntactical theories, there are some aspects of varieties of English, morphology and phonetics in their book. However, English Grammar: Understanding the Basics, by Altenberg and Vago [4], and Oxford Guide to English Grammar, by Eastwood [5] have limited the contents in their books to only basic syntactic issues such as: word classes, phrases, clauses, and sentences. Oxford Guide to English Grammar focuses on systematic presentation of grammatical forms, their meanings, and how they govern the choice of grammatical patterns as used in standard British English [5]. Altenberg and Vago [4] on their part have discussed English grammar in "as simple and straight-forward" way as possible. Therefore, their book has chapters on kinds of words, phrases, subjects, objects, and sentences [4]. Introducing English Grammar is one English grammar book that has discussed grammatical contents in a slightly different way [1]. The first impression of the book was published in Great Britain by Hodder Education, a Hachette UK Company, located in London. The contents of the book are segmented into eleven parts. This current paper reviews the contents in a subject-by-subject way, by projecting the uniqueness that each segment (chapter) presents. As already mentioned in the abstract, the four frameworks that the current review paper is hinged are Introduction, Thesis, The Chapters, and Conclusion.

\section{The Thesis}

Thesis statement is an essential component of introductory section of every essay [6]. The thesis statement of Introducing English Grammar [1] has been conspicuously stated. The book aims at imparting to students some terminologies that they may need in order to discuss language conveniently. The writers focus on exposing readers to introductory information on sentence structure of English. The book also aims at sensitising readers in realising that the issues they study in English grammar are around them. Most of the English language input activities can now be accessed through music, television, and other mass media. Consequently, the authors use real-life examples from a magazine called: The Big Issue. A key message the book seeks to send across is that good grammars do not exist in native English-language speaking countries only. Readers expected to patronise the book are: English grammar teachers, foreign language teachers, speech therapists (who do language analysis), and those studying formal grammar.

\section{The Chapters}

This section of the paper reviews the contents of the book, which have been 
thematically segmented into eleven chapters. The critique of some of the chapters includes comparative analyse of contents from other English grammar materials.

\subsection{Chapter One: Introduction: The Glamour of Grammar}

The introductory chapter of the book, the glamour of grammar, exposes readers to some topics, which pose a lot of mystery and perplexity for students. Chapter one, the core of the book, has six sub-themes. In theme one, purpose and nature of grammatical description, the writers enumerate some reasons why students may want to study the grammar of a language. The writers indicate that the grammar of every language can facilitate the effective learning of the language. For example, the learning of English language grammar would enable linguists to label structures as grammatical or ungrammatical. Let us consider these structures:

(a) Oscar is eenlieve maarnietzoslimme poes [1].

(b) Maybe he's dead? Killed his self getting out of the bath [1].

(c) That it's eerie tin rusted Milo uncanny [1].

(d) Tear im wrapper (Have sex with her) [7] as cited in [8].

(e) Many parent don't... (Many parents don't.../A parent doesn't...) [9].

It is obvious that examples (a) and (c) are not considered as English language grammatical structures. The first sentence in example (b) is a statement. So, the question mark at the end of that simple sentence is out of place. The second sentence in example (b) has two grammatical flaws. The entire sentence is a null-subject construction, and cannot stand alone as a sentence. Again, "his self" (himself) does not exist in Standard English (SE). Example (d) is an example of a Nigerian Pidgin structure. Example (e) does not conform to grammar rules of English language. Therefore, a study of grammar rules, would disclose some grammatical defects to learners of English language.

In the second theme, Standard English and Variation, Börjars and Burridge distinguish between Standard English (SE) and its variations. Different dialects exist within the context of different speakers of English language. But, in terms of formality and the way societies operate, SE has proved to be the most important dialect. The authors argue that SE is a dialect of English language that has the greatest clout. Since SE operates with certain contexts: economic, political, and social, it has now developed as a codified global lingua franca. This explains why it is recorded in grammars, dictionaries and style books. In most formal settings, English language speakers would be expected to use SE. This doesn't mean that the structures of the other varieties of English language (for example, sentence (d) in 3.1) are "bad English" per se. Though such structures do not have a place in SE; semantically, they are correct in their own settings. Hence, Börjars and Burridge reiterate an argument in varieties of English, which states that "...all dialects are equally good for the purposes they serve" [1]. This argument is in consonance with Owusu et al. [8] that argued that "New Englishes are not 
necessarily deviant forms; but they are right in their own contexts, especially when they serve the linguistic needs of their respective communities".

In the last section of this sub-theme, the book indicates that time and variation across space are two dimensions that have influenced English language. As time went on, we have experienced significant shift in grammar, words, and punctuation even within one's own lifetime. Geographical and social variation across space have also triggered a growing multiplicity of Englishes in the form of hybrids, dialects, nativized varieties, pidgins, and creoles as illustrated in example (d) of section 3.1. For example, social parameters like age, sex, sexual preference, socio-economic class, education and occupational status of speakers will mostly determine the way sounds, vocabulary and grammar will vary. This, according to the book, makes English a bit of a fiction, as there is no one English, no one uniform entity with a static and a rigid set of linguistic characteristics. The third theme, English rules, OK; explores two different approaches to grammar: prescription and description. It a common knowledge that prescriptive grammar tells you how you ought to speak and write. Here, the book [1] describes materials about prescriptive grammar as a "hodgepodge of 'do's' and 'don'ts' about sentence structure, word meaning and word usage". The authors cite some examples of prescriptive grammar as:

(f) Do not use lay as an intransitive verb.

(g) Do not use an apostrophe for possessive "its".

(h) Do not use data as a singular noun.

In explaining example (f), the authors cite a case of "to lay or to lie" to elucidate prescriptive grammar vividly: the verb "lay" is transitive; so hens lay eggs [1]. "Lie" is intransitive; you can't "lie" something. So, linguistic conformists of prescriptive grammar would label the structure: "...to lay down with dogs..." instead of "...to lie down with dogs..." as an exposition of illiteracy. At the onset of sub-theme three, English rules, OK, the book creates an impression of a probable juxtaposition of prescriptive and descriptive grammar. However, the information the authors provide in this sub-theme of the book is skewed to only prescriptive grammar, as detailed illustrations of descriptive issues are vividly omitted. This omission may be due to the fact that the book clearly has a scope which is captured in the thesis-to use one type of English, Standard English, so that, the book would focus on the structure of English work, given that it will inexorably appeal to varied reading audience.

The forth sub-theme, why study English grammar, points out five reasons why linguists might want to compose descriptive declarations about English. These linguists consider a number of factors: typology, universal grammar, speech therapy, foreign language learning, and stylistics.

According to the authors, the first point that warrants the study of English is typology, which is the study of the similarities and differences that exist between languages. Through thorough studies of grammars of several languages, linguistics in this field can construct empirical statements about variances and connec- 
tions that occur among languages. Linguists who are interested in executing this kind of comparative analysis of languages are referred to as typologists. Also, the authors argue that common typological characteristics of languages are the result of genetic inheritance (though not absolute) and language change (either through motivation or contact) [1]. This section of the book also indicates that historically, English is a Germanic language. And specifically, it is a West Germanic language which is related to other Germanic languages, like Dutch or Swedish. For example, in a typological analysis of English and Italian, you realise that English is one of those languages which desire a subject. English is typically an SVO language like Chinese. So, structures (i) and (j):

(i) Am coming (i.e. I am coming/I'm coming)-English.

(j) Is raining (i.e. It is raining/It's raining) - English.

are normally seen as ungrammatical structures of English, since they do not possess obligatory subjects that SE requires, but structures $(\mathrm{k})$ and (l) may be accepted in formal Italian usage, since the use of a subject is not required in this context, though Italian is also an SVO language:

(k) Mangio (I eat-1st person singular)-Italian.

(l) Piove (rains-i.e. It rains)-Italian.

In an empirical study of three languages-English, Akan, and Safaliba ${ }^{1}$-it was realised that English shares some similarities with Safaliba [10]. That is, in terms of the location of determiners in noun phrases-both languages are pre-determiner languages. It was also realised that Akan and Safaliba possess several locative verbs which are in consonance with some locative notions which are derived from parts of the human body. Moreover, English has prepositions which typically occur at the beginning of prepositional phrases; but Akan and Safaliba recognise postpositions, which usually occur at the concluding section of adpositional phrases [10]. For some linguists, one reason that justifies the study of English grammar, according to the book, is the theory of Universal Grammar (UG). Teaching and learning of grammar has the propensity of contributing knowledge on theories on UG. This theory, which is credited to Noam Chomsky, has a basic postulation - a specified set of structural procedures are innate to humans. Thus, linguists study grammar to find out how the human brain deals with language. Linguistic research, usually, delves into UG which is perceived as an abstract entity. One of such innate studies is Noam Chomsky's Language Acquisition Device (LAD) theory. According to this theory, the human mind possesses a thin wire-like device, which is responsible for processing language. This device usually atrophies or diminishes with age. This explains why children are able to acquire languages with ease, as compared with adults who even struggle to learn a language.

${ }^{1}$ Safaliba is a Gur language which is spoken in the western part of the Northern region of Ghana [11]. Akan is a Kwa language. Kwa happens to be one of the branches of Niger-Congo language family. The Akans are the largest ethnic group in both Ghana and the Ivory Coast. Therefore, in Ghana, its speakers are many. The dialects of Akan include: Fante (or Fantse), Akuapem, Asante, Agona, Bron, Wasa, Akyem, and Kwahu [12]. 
Again, the book explains why speech therapy is another reason for studying grammar. Speech therapy or communication disorder study has to do with individuals whose language is different from the normal. Learning grammar is a motivation for speech therapists to develop strategies that can help in dealing with challenges associated with speech therapy. In order to study the grammar of "unusual language" it is imperative for one to study the structures of the usual language. The book, thus, aims at teaching terminologies used to describe grammar.

Moreover, foreign language learning is another motivation for studying English grammar. The book explains that knowledge of English grammar is essential for the teaching and learning of most foreign languages. For example, native speakers of English language have a way of scientific thinking about their language in a subconscious matter. However, the challenge arises when they are confronted with issues on the field. Therefore, a conscious study of English language would enable them to deal with the challenges that arise on the field.

Stylistics, (the branch of linguistics devoted to the study of how language is used in literature), according to the book, is another motivation for studying English grammar. The authors of the book claim that information they have provided is of great benefit to individuals who have interest in literature, and desire to study it to the highest level. The genres of literature-prose, drama, and poetry-are built up of language. So, a detailed study of language is advantageous to the study of literature. Since stylistics includes the study of effective communication, or effective writing, a comprehensive study of grammar has the propensity of working on one's written ability, such as speech or report writing.

The fifth sub-thematic area of chapter one is English language in the workplace. Here, the book itemises a number of functions English language plays in various working fields: film industry, writing, information technology, advertising and marketing, safety measures, and the law. The sixth sub-thematic area of chapter one, the branches of linguistics, summarises the core parts of linguistics. These are Phonetics/Phonology, Morphology, Syntax, Semantics, and Pragmatics.

\subsection{Chapter Two: The Structure of Sentences}

Chapter two has seven thematic areas: the structure of words, how do we know sentences have structure, constituency tests, three additional test, nested constituents, representing structure, and points to remember. In the first sub-theme of chapter two, the structure of words, the book briefly summarises the two main morphemes of free and bound. The authors highlight inflection and derivation as two main types of word-building activities involving bound morphemes. Here, the authors cite instances of inflectional and derivational affixes as word formation mechanisms. Compounding is another word-building process that the book stresses. However, the authors did not capture other traditional word formation processes such as clipping, blending, borrowing, conversion, redupli- 
cation and acronym as cited in Sloat and Taylor [13] and Wiredu [14]. In the second sub-theme, how do we know sentences have structure, the authors stress that sentences have a group of words which "go together", and this ideology is referred to as constituents [1]. Thus, a constituent is a string of words that forms a unit within a phrase or a sentence [1]. These constituents can come together to form another constituent to make a sentence complete. In the third sub-theme of chapter two, the authors mention substitution, unit of sense/sentence fragment, movement, and co-ordination as four tests conducted to verify whether the string of words in a sentence can function as a unit. In the fourth sub-theme, three additional tests, the authors list reduction, omission, and intrusion as additional tests conducted to verify if sentences have structures. The fifth sub-theme of chapter two, nested constituents, highlights various examples and tasks on substitution, co-ordination, sentence fragment, reduction, omission, and intrusion. The sixth sub-theme, representing structure, describes trees and brackets as the two common ways of indicating constituent structures. The seventh sub-theme is a recapitulation of the entire chapter two. This sub-theme has exercises on morphemes, constituents, and structural ambiguity.

\subsection{Chapter Three: The Words of English}

In chapter three, the words of English, the authors categorise the classes of words into two categories of major and minor. The major categories include nouns, pronouns, verbs, adjectives, and adverbs. With the exception of pronouns, all the other members in this category have information on semantic characterization, morphological features, and syntactic behaviour. The separate semantic, morphology, and syntactic segmentation for nouns, verbs, adjectives, and adverbs, make this grammar book, a distinctive one [1]. The minor categories as projected by the authors are preposition, conjunction, and determiners. Each of these minor categories has semantic and morphological features. However, interjection is conspicuously missing from this chapter as a word class. This chapter ends with a summary of the main points on the major and minor word classes and their sub-categories. The categorisation of word classes in this chapter is different from what we see in Quirk and Greenbaum, where word classes are categorised into closed-system and open-system items [3]. The closed-system items (i.e. article, demonstrative, pronoun, preposition, conjunction, and interjection) do not usually welcome new members into their category. The open-class system (i.e. noun, adjective, adverb, and verb) are items that usually welcome new members into their category [3].

\subsection{Chapter Four: Functions within the Clause}

In chapter four, functions within the clause, the authors stress basic clausal functions of the predicate, subject, object, predicative complement, adverbials, and the trees. On the subject, the authors highlight five structural characteristics that most subjects possess: subject-operator inversion in questions, verb agreement, 
case, phrasal category, basic position and the special case of "there". About their contribution to objects, the authors underline the two types of objects, direct and indirect, with several instances. Again, they mention passive, case, phrasal category and basic position as some vital properties of the object. On the predicative complement, they cite some distinguishing characteristics as co-reference, number agreement, phrasal category and basic position. The characteristics of adverbials have been cited as optional status, flexible word order, stacking and phrasal category. Besides, the three sub-types of adverbials-adjuncts, disjuncts and conjuncts are explained with examples.

\subsection{Chapter Five: Different Sentences Types}

Chapter five has six main sub-thematic areas of declaratives, interrogatives, imperatives, exclamatives, echoes, and the trees. With few instances, the authors explain the four main types of sentences: declaratives (statement), imperatives (command), interrogative (question), and exclamatives (emotional conveyance). They indicate that the echo construction comes in when a participant of a discourse repeats a structure given by the first person. The repetition of the structure is such that a wh-word replaces a VP:

(m) This cartoon has been cancelled. (Declarative)

This cartoon has been what? (Echo response)

(n) What did it cost them? (Wh-interrorgative)

What did it cost who? (Echo response)

(o) Pay no taxes! (Imperative)

Pay no what? (Echo response) [1]

\subsection{Chapter Six: The Verb Phrase}

Chapter six discusses the Verb Phrase (VP) from seven sub-thematic perspectives of constituency of verb strings, time and tense, lexical verbs and auxiliary verbs, auxiliary verbs, lexical "have", "be" and "do", classes of lexical verbs and the trees. Here, we think the authors' categorisation of VP lacks coherence. The authors could have done better, if they had merged all the information on three of the sub-themes (i.e. auxiliary verbs, lexical "have", "be" and "do", classes of lexical verbs) under two sub-themes of lexical verbs and auxiliary verbs. In our opinion, their decision to create such sub-divisions amounts to wrong fragmentation of ideas or points. We find it difficult comprehending any justification for creation of some of these sub-themes.

\subsection{Chapter Seven: The Noun Phrase}

In Chapter seven, the Noun Phrase (NP), the authors discuss the contents in sub-topics of how to spot an NP, determiners, pre-modifiers, pre-determiners, post-modifiers, complements, and the trees. Mostly, the examples cited in this chapter are texts from an article in The Big Issue. On identification of an NP, the authors state that if a structure can be replaced by pronouns, then it has the 
propensity to be labelled as an NP. Apart from this, the authors cite several characteristics of NP. About the information on trees, the authors move that one of the characteristics of determiners (except possessive NPs) is that they cannot be modified. Hence, the determiner should occur underneath a Det node and not a DetP node [1]. The authors also mention that there exist arguments in favour of considering the determiner, rather than the noun, the head, so that many theoretical approaches assume that the determiner, the, is the head of an NP like the astronaut and the whole phrase is DP, rather than an NP [1]. The authors, accordingly, provide readers with a basic tree about their view for a full NP as Figure 1.

\subsection{Chapter Eight: Clauses within Clauses}

In chapter eight, clauses within clauses, the authors segment the contents into four categories of: clauses, finite sub-clauses, non-finite clauses, subjectless clauses, and the trees. The introductory section of this chapter, clauses, has been dedicated to classification (dependent and independent clauses), explanation and definition of clauses. Here, the authors argue that a definition that sees a sentence as a unit formed around a lexical verb, containing all the bits that the verb requires as well as any optional bits the speaker has chosen to include is erroneous. According to them, this is strictly a definition of a clause. The finite sub-clauses, as a sub-section of chapter eight, looks at declarative, interrogative, relative, and that-clauses. On non-finite clauses, they discuss the bare infinitive, to-infinitive, -ing participle, and passive participle clauses. The sub-section, subjectless clauses, has been dedicated to issues on control and controlled subjected, object control and subject control, and dangling participles.

\subsection{Chapter Nine: Beyond the Sentence}

In chapter nine, beyond the sentence, the authors list some communicative purposes of English structures. To them, "the ways in which we distribute our bits of information in a text, in order to provide the right sort of cues to help our audience follow and interpret a piece of discourse appropriately" is called communicative structure [1]. In short, this is how English speakers package the
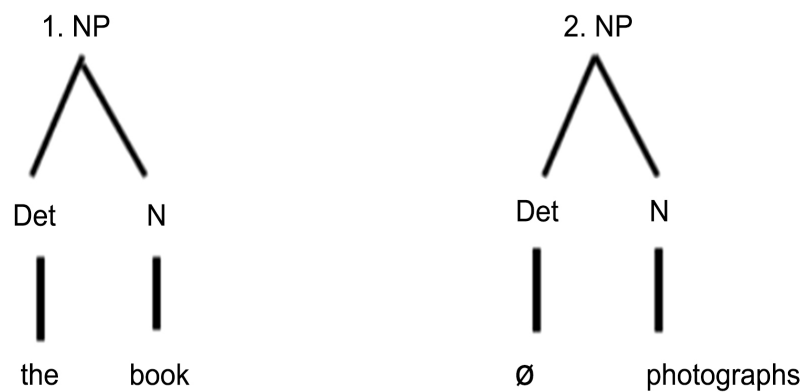

Figure 1. A tree representation of an NP [1]. 
contents of their communication. Consequently, the authors present two communicative purposes of information packaging, and discourse strategies. On information packaging, the authors explain three basic principles for organising information in a sentence. These principles are "given information comes before new", cohesive texts: topic comes before comment, and front-focus: initial position for extra focus.

The two basic kinds of information in writing: new and given (or old) information, can refer to what has happened earlier in a text (new), or it can be given in the sense that it is common knowledge. Information packaging also has to do with topic and comment. The topic (or theme) is the part of the sentence which shows what is being written or talked about. The rest of the sentence that makes a statement about the topic is called the comment (or rheme). The third aspect of information packaging is front-focus (initial position for extra focus). This is where readers focus on elements at the beginning of a sentence.

On discourse strategies, they cite given-new strategies and focus strategies. Given-new strategies highlight sub-topics such as passives-creating new subjects, different semantic types as subjects, "tough" movement, existentials, and extraposition. Focus strategies discuss cleft constructions, fronting, left-dislocation, and right-dislocation.

\subsection{Chapter Ten: Grammar at Work}

In chapter ten, the grammar at work, the authors introduce the notion of registers-varieties associated with specific contexts or purposes. In the introduction of the chapter, they state that our language manners differ in response to a complexity of diverse situational factors such as the relationship between speakers and their audience, setting (formal or informal), subject matter, and the medium (spoken or written). Consequently, the chapter briefly expounds three register types of speech versus writing, E-Speak (somewhere between speech and writing), and occupational varieties.

\subsection{Chapter Eleven: English Worldwide}

Chapter eleven, English worldwide, has five main sub-thematic areas of new Englishes: Indian English, other Englishes, variation in the native Englishes, vernacular universals, and the future of Standard English. In the introductory section of this chapter, the authors state that the world is becoming progressively universal in orientation. Consequently, the spread of English around the globe has activated an escalation of diversity in the form of "hybrids, dialects, nativized varieties, pidgins and creoles, all influenced by the many different environments and languages English has come into contact with" [2]. In the five main sub-themes of this chapter, the authors explain some of the features and characteristics of these new Englishes. The authors also claim that globalisation necessitates international intelligibility (a world standard), and the protection of national identity, however, it nurtures diversity in the form of distinctive Englishes. 


\section{Conclusion}

This paper has reviewed Börjars \& Burridge's Introducing English Grammar book in a comprehensive manner. Since the book is made up of eleven chapters, we decided to do a subject-by-subject discussion of each of the chapters. With this approach, we were able to critique most of the sub-topics of the eleven chapters of the book. The thesis of the book focuses on conveying to readers some vocabulary items that they may require in discussing language appropriately. Besides, the thesis of the book sensitises readers that English language input activities are not far-fetched; in that they emanate from print and electronic media, and most of the entities around readers. However, in the introductory chapter, we can witness a palpable twistiness of information of prescriptive grammar as against descriptive grammar. Again, information about some of the word classes (for example, interjection) was not captured. That notwithstanding, we perceive the book as a material with robust contents, worthy of study at the tertiary level of education across the globe.

\section{Conflicts of Interest}

The authors declare no conflicts of interest regarding the publication of this paper.

\section{References}

[1] Börjars, K. and Burridge, K. (2010) Introducing English Grammar. 2nd Edition, Hodder Education, London.

[2] Owusu, E. and Afram, S.C. (2020) Ellis' (2005) Ten Principles for Language-Teacher Education: A Review from the Ghanaian Context. International Journal of Linguistics, Literature and Translation, 2, 366-372.

[3] Quirk, R. and Greenbaum, S. (2012) A University Grammar of English. 7th Impression, Pearson Education in South Asia, India.

[4] Altenberg, E.P. and Vago, R.M. (2010) English Grammar: Understanding the Basics. Cambridge University Press, Cambridge. https://doi.org/10.1017/CBO9780511794803

[5] Eastwood, J. (2002) Oxford English Grammar. Oxford University Press, Oxford.

[6] Owusu, E. and Adade-Yeboah, A. (2014) Thesis Statement: A Vital Element in Expository Essays. Journal of Language Teaching and Research, 5, 56-62. https://doi.org/10.4304/jltr.5.1.56-62

[7] Abdullahi-Idiagbon, M.S. (2010) The Sociolinguistics of Nigerian Pidgin (English) on University Campus. Ife Studies in English Language. Department of English, Obafemi Awolowo University. Ife, 8, 50-60.

[8] Owusu, E., Kyei Adoma, S. and Oti Aboagye, D. (2016) Sociolinguistics of the West African Pidgin Englishes: A Review. Studies in English Language Teaching, 4, 534-550. https://doi.org/10.22158/selt.v4n4p534

[9] Owusu, E., Agor, J. and Amuzu, E. (2015) Second Language Learners' Family Background and Their English Writing Competence: The Case of a Private Tertiary Institution in Ghana. Studies in English Language Teaching, 4, 466-486.

https://doi.org/10.22158/selt.v3n4p466 
[10] Owusu, E. (2015) Basic Locative Construction and Simple Clause Structures of English, Akan, and Safaliba. International Journal of Language and Linguistics, 5, 178-191.

[11] Schaefer, P. and Schaefer, J. (2003) Functional/Typological Overview of the Morphology and Syntax of Safaliba. Institute of African Studies (for GILLBT), Legon, Accra.

[12] Saah, K.K. (1994) Studies in Akan Syntax, Acquisition, and Sentence Processing. Ph.D. Thesis, University of Ottawa, Ottawa.

[13] Sloat, C. and Taylor, S. (1985) The Structure of English Words. 3rd Edition, Kendall Hunt Publishing Company, Dubuque.

[14] Wiredu, F.J. (1999) Organised English Structure. Academic Publications (Ghana) Limited, Accra. 